\title{
La interdicción sobre la izquierda en español: su reflejo en los diccionarios
}

\author{
DAVID ISAAC DEL RÍO ENTONADO
}

Universidade da Coruña

Para cualquier hablante del español actual resulta evidente que los conceptos de $i z$ quierda y derecha encierran una oposición significativa que va mucho más allá de la mera diferencia espacial. Si nos fijamos en palabras asociadas a uno y otro término apreciamos claramente que todo lo relacionado con la derecha goza de claras connotaciones positivas, mientras que lo asociado a la izquierda siempre se relaciona con aspectos negativos. Basta con acudir a las definiciones aportadas por la última edición del DRAE para los términos derecho, diestro, izquierdo o siniestro, por ejemplo, para obtener datos objetivos sobre este aspecto ${ }^{1}$.

Pues bien, el objetivo del presente artículo es precisamente recoger una amplia lista de aquellos términos y expresiones que de alguna manera dan prueba de lo arraigado de esta concepción a lo largo de la historia del español y demostrar la significación negativa que poseen a partir del análisis de su visión en los diccionarios.

\section{INTRODUCCIÓN: LA SIMBOLOGÍA}

Antes de entrar en materia puramente lingüística, es necesaria una pequeña introducción sobre la simbología que origina este fenómeno de la interdicción. Sin adentrarnos demasiado en un tema verdaderamente complejo sobre el que no da tiempo a profundizar en estas páginas, podemos afirmar que la asociación de la izquierda con lo negativo y la derecha con lo positivo es una constante en la mayor parte de las culturas del mundo desde hace muchos siglos. No cabe duda de que en nuestra cultura destacan las continuas referencias que aparecen tanto en el Antiguo como en el Nuevo Testamento en las que la izquierda simboliza siempre el mal, el pecado y la condenación. Tomemos como ejemplo representativo la célebre cita sobre el Juicio Final en la que se separa a los elegidos para la vida eterna, situados a la derecha de Cristo, de los conde-

* La información aportada en este artículo se enmarca dentro de una investigación mayor que ha dado lugar a una tesis doctoral, en la que se analizan con detenimiento las consecuencias en el español de la interdicción sobre la izquierda, con especial atención a la visión diacrónica.

${ }^{1}$ Comprobemos cuáles son algunas de esas definiciones. Para derecho, encontramos, por ejemplo: «recto, igual, seguido, sin torcerse a un lado ni a otro»; «justo, legítimo»; «fundado, cierto, razonable». Para diestro: «hábil, experto en un arte u oficio»; «sagaz, prevenido y avisado para manejar los negocios, sin detenerse por las dificultades»; «favorable, benigno, venturoso». En cambio, en izquierdo aparece: «torcido (que no es recto)». En siniestro, por su parte: «avieso y malintencionado»; «infeliz, funesto o aciago»; «daño de cualquier importancia que puede ser indemnizado por una compañía aseguradora»; «propensión o inclinación a lo malo; resabio, vicio o dañada costumbre que tiene el hombre o la bestia» (DRAE-2001: s. v.). 
nados, colocados a su izquierda (Mateo 25, 31-46). Pues bien, esta visión del cristianismo se puede extrapolar a una gran cantidad de religiones y supersticiones ligadas a otras culturas repartidas por todo el mundo ${ }^{2}$.

\section{LA INTERDICCIÓN}

La constante visión negativa de la izquierda a lo largo de la historia ha provocado que los diferentes significantes relacionados con este significado se hayan visto fuertemente condicionados. Las huellas de esta interdicción son ya evidentes desde el indoeuropeo, y se pueden apreciar claramente tanto en la familia de lenguas romances como en otras familias lingüísticas del mundo.

Se considera a Meillet como el primero en llamar la atención acerca de la diferencia que se aprecia en distintas lenguas indoeuropeas entre los términos utilizados para designar los significados 'derecha' e 'izquierda': mientras que los primeros forman un grupo homogéneo que comparte la misma raíz, los segundos están formados por expresiones muy distintas y variadas. Meillet ya admitió el fenómeno de la interdicción para explicar esta gran variedad de significantes para la 'izquierda' en estas lenguas (1948: 290-291).

El latín muestra una vez más la disparidad entre los significantes pertenecientes a uno y otro significado: frente a DEXTER, tenemos LAEUUS, SCAEUUS y SINISTER. De los tres términos relacionados con 'izquierda', solamente SINISTER ha pasado a las lenguas románicas tras haber sustituido a sus otros dos «contrincantes»; probablemente, el propio término SINISTER nació como sustituto eufemístico de los otros dos términos (Ernout-Meillet, 1985: s. v.; Uría, 1997: 166-169).

Pero los herederos de SINISTER también han sufrido las consecuencias de la interdicción. Como veíamos al comienzo del artículo, siniestro en español ha adquirido una carga peyorativa importante, de manera que la mayor parte de las acepciones con las que se utiliza hoy en día tienen un significado de base negativa; de hecho, el sentido originario espacial ha quedado relegado a empleos especiales y muy poco frecuentes. Esta situación es análoga a la que viven la mayoría de las lenguas románicas.

Así, se asume que hoy en día el término izquierdo del español, que tiene sus análogos en otras lenguas cercanas, se tomó del vasco EZKER ${ }^{3}$. Corominas y Pascual aseguran que «apenas puede haber duda de que estamos ahí ante el resultado de una de tantas interdicciones o tabús que han afectado la palabra para 'izquierdo', a causa del mal agüero que envuelve» (DECH: s. v. izquierdo).

${ }^{2}$ Para consultar más acerca de esta simbología puede confrontarse un estudio ya antiguo pero que contiene importante información como es el de Hertz (1990). Además, hay dos volúmenes que recogen numerosos artículos que enfocan el asunto desde las distintas perspectivas de diferentes culturas: Needham (1973) y Kourilsky-Grapin (1971).

${ }^{3}$ Lo que sí parece suscitar más problemas es el origen del propio vocablo esker; para más información, $c f . D E C H$ (s. v. izquierdo), Tovar (1959: 26-31). 


\section{LOS TÉRMINOS}

A continuación, veremos ya una amplia muestra de términos y expresiones en los que se aprecia la influencia que ha ejercido en nuestra lengua la simbología que estamos analizando 4 .

\subsection{Siniestro}

Ya en Autoridades 1739 se recogen varios sentidos negativos del término. Dos de ellos como adjetivo: «viciado, avieflo, ò mal intencionado» y «cofa infeliz, funefta, ò aziaga». Y uno más como sustantivo: «refabio, vicio, ò mala coftumbre, que tiene el hombre, ò la beftia». Los tres sentidos se mantienen en el DRAE-2001, donde se amplían las acepciones de significado negativo, en concreto en dos empleos como sustantivo.

El primero es el de «daño de cualquier importancia que puede ser indemnizado por una compañía aseguradora». Un significado análogo a este aparece por primera vez en la edición académica de 1852: «Comercio. Avería grave ó pérdida de mercancías, especialmente en el mar, por naufragio ú otro contratiempo». Hay que tener en cuenta que esta acepción sufre cambios en la nueva edición aún sin publicar del $D R A E$, donde aparece definida de esta forma: «Suceso que produce un daño o pérdida material considerable».

La otra acepción de 2001 es: «Derecho. En el contrato de seguro, concreción del riesgo cubierto en dicho contrato y que determina el nacimiento de la prestación del asegurador». Es la primera vez que el diccionario académico recoge este significado.

El $D E A$ y el $D U E$, a pesar de establecer diferencias con la versión académica - por ejemplo, al no recoger empleos menos frecuentes o repartirlos de manera diferente en acepciones y subacepciones-, no amplían estos sentidos negativos que hemos comentado y que ahora vamos a ilustrar con ejemplos.

${ }^{4}$ La metodología escogida para explicar cada uno de los términos es muy sencilla. Por un lado, se analizará la visión que recogen los diccionarios de cada uno de ellos. Nos centraremos en tres diccionarios importantes del español actual, como son la $22^{\mathrm{a}}$ edición del Diccionario de la lengua española de la RAE (DRAE-2001), el Diccionario de uso del español (DUE) de María Moliner y el Diccionario del español actual (DEA) de Manuel Seco, Olimpia Andrés y Gabino Ramos. También se tendrán en cuenta los cambios que ofrece la nueva edición del DRAE — aún sin terminar- en su página de Internet.

Además de esta información actual, se contrastará la percepción diacrónica de los más importantes diccionarios de siglos anteriores; para ello, utilizaremos como herramienta el Nuevo tesoro lexicográfico de la lengua española (NTLLE), compilación de la RAE que ofrece, además de todas las obras lexicográficas publicadas por esta institución, distintos diccionarios de la lengua española que datan desde el siglo $\mathrm{XV}$. Nos centraremos sobre todo en las primeras apariciones de los sentidos comentados.

Por otra parte, para ilustrar con ejemplos los empleos de los términos y expresiones manejaremos los dos corpus que ofrece la Real Academia Española en su página de Internet: el Corpus diacrónico del español (CORDE), para los textos datados desde el origen del idioma hasta 1975, y el Corpus de referencia del español actual (CREA), que recoge pasajes comprendidos entre 1975 y el año 2004. Intentarán mostrarse los casos más antiguos hallados en contraste con empleos actuales. Esta búsqueda en los corpus ha sido prácticamente exhaustiva, ya que, como he indicado, en este artículo reflejo los resultados obtenidos en un análisis pormenorizado de los términos a los que aludo. 
'Viciado, avieso, malintencionado':

Los primeros ejemplos claros con este sentido, sin ambigüedades ${ }^{5}$, los encontramos en el siglo XV. Por ejemplo:

E querer agora vosotros repreender lo que entonçes loastes e prouastes, vien paresçe la yntención syniestra con que a ello vos mobedes (Pedro Carrillo de Huete, Crónica del halconero de Juan II, a 1454, p. histórico-documental).

En la actualidad podemos señalar casos como este:

Contradiciendo el apuro anterior, empezaron a contarle una historia de intoxicaciones masivas que había circulado muchos años atrás: una potencia de las que codiciaban el Canal antes de que estuviera terminado planeó la siniestra maniobra de envenenar a toda la población del país, al menos a la urbana, para tomar el poder bajo forma de protectorado en el caos consiguiente (César Aira, Varamo, 2002, ficción).

'Infeliz, funesto, aciago'

Ya en el siglo XIV encontramos algún caso:

$¡ \mathrm{O}$, hermano! ¿Et a que te constrines et te aturmentas por tanto dolor? Car encara que justa razon de dolor te mueua, empero de uaron sabio non se pertenesce mostrar defuera los mouimientos et turbaciones de su coraçon, porque el dolor que paresce defuera en las sinistras cosas prouoca mas a los amigos a dolerse et engendra mayores goyos en los enemigos (Juan Fernández de Heredia, Historia troyana, 13761396, p. histórico-documental).

Del CREA podemos destacar:

Será un oráculo que anuncia siniestras consecuencias -contestó otro (Terenci Moix, El arpista ciego. Una fantasía del reinado de Tutankamón, 2002, ficción).

'Vicio, mala costumbre'

Aparece con claridad en el siglo XV:

Soys en todo tanto diestro

qu'en la verga de Jesé

al que toma algún siniestro

sabéys tornar a la fe.

Sabéys bien buscar el bado

en aguas turbias, esentas,

y pasar el mar ayrado

en sus mayores tormentas.

(Pero Guillén de Segovia, Respuesta a Gómez Manrique [Cancionero de Gómez Manrique], 1470-c 1480, literario).

No se trata de un empleo ni mucho menos frecuente en la actualidad:

Decir que es dificultosa de hallar es la primera alabanza de la buena mujer. No se tendría en buena si hubiera muchas buenas o si en general no fuesen muchos sus $s i$ -

${ }^{5}$ Se han hallado algunos casos que podrían corresponderse con este sentido en siglos anteriores, pero el contexto no es lo suficientemente claro como para asignarles un sentido unívoco. 
niestros malos. Las hay cerriles y libres como caballos (Eladia González, Quién como Dios, 1999, ficción).

'Accidente, desgracia'

A pesar de que este empleo no aparece recogido en Autoridades, lo encontramos ya en el corpus desde el siglo XV:

Agora veo, señor, que si acahesçiesse algúnd siniestro, lo que a Dios no plega, vuestra merçed quiere perder el oro, e aun la fortaleza... (Crónica de Don Álvaro de Lu$n a$, anónimo, $c$ 1453, p. histórico-documental).

En la actualidad es uno de los empleos más frecuentes:

A consecuencia del siniestro, Tráfico cortó el carril izquierdo durante tres horas, aunque la decisión no afectó a la circulación porque no provocó retenciones ( $\mathrm{La} \mathrm{Voz}$ de Galicia, prensa, 15-1-2004, política y economía).

'Daño sufrido por algo asegurado'

En el caso de este último sentido comentado preferimos la definición del $D E A$, que hace notar más claramente la base peyorativa. Encontramos algunos ejemplos algo dudosos con este sentido en el siglo XIX, pero es en el siglo XX donde se empiezan a notar sin ninguna ambigüedad, como en este pasaje, en el que apreciamos claramente también esa base negativa:

El régimen de asistencia es aquel por el cual el Estado directamente, con sus recursos, sin cálculos ni bases actuariales, se encarga de proporcionar a los trabajadores los auxilios necesarios cuando el siniestro se produce (muerte, vejez, invalidez, paro, etc.) (Carlos García Oviedo, Tratado Elemental de Derecho Social, 1946, p. jurídica).

Un ejemplo más actual puede ser este:

Europrotección de Pagos es un seguro que asume el pago de las cuotas de amortización o de aquel capital pendiente de amortizar de su crédito o hipoteca, en el caso de que se produzca un siniestro por cualquiera de los riesgos que usted desee asegurar (Página web, 1999, miscelánea).

\section{Siniestramente}

Ya en Autoridades en 1739 aparecía con el significado de «malamente, è indebidamente». Por su parte, el $D R A E$ 2001, el $D E A$ y el $D U E$ coinciden en este caso en la definición: «De manera siniestra». El problema que plantea esta definición es su ambigüedad, pues acabamos de ver que siniestro, como adjetivo con sentido peyorativo, puede tener varios sentidos. Los dos señalados principalmente por los diccionarios son el de 'viciado, avieso, malintencionado' y el de 'infeliz, funesto aciago'. Veámoslo, pues, con ambos sentidos.

Comenzando por el CORDE, apreciamos el primero de estos sentidos en este fragmento:

Todo lo demás que se dice en la Epístola (por más que se quiera interpretar siniestramente) no puede en modo alguno tenerse por ofensa de aquella Nación, pues todo su contexto se dirige a persuadir que, ya que también en Francia hay Escritores que son más dignos de desprecio que de atención, es justo que practiquen con nosotros aquella christiana 
caridad y prudente moderación que es debida, y no nos traten con tanto y tan general desprecio; acordándose que no es conforme al Evangelio notar tan sin excepción los defectos agenos y olvidar casi enteramente los proprios (Ignacio de Luzán, Defensa de España y participación en la campaña contra Gregorio Mayans, 1742, p. didáctica).

El segundo lo vemos, por ejemplo, en:

Algunos dicen que cuando se acerca el tiempo en que se celebra el nacimiento de nuestro Redentor, este pájaro matutino canta toda la noche, y que entonces ningun espíritu se atreve á salir de su morada: las noches son saludables, ningún planeta influye siniestramente, ningún maleficio produce efecto, ni las hechiceras tienen poder para sus encantos: tan sagrados son y tan felices aquellos dias! (Leandro Fernández de Moratín, Traducción de Hamlet, Shakespeare, 1798, literario).

Pasando al $C R E A$, encontramos ambos sentidos en estos dos pasajes, respectivamente:

¿Quién diablos iba a sospechar que quienes la rescataron de una muerte posible habían terminado causándosela con saña? No sé si el Ministro Arrue tuvo o no que ver con el asunto, pero todo fue siniestramente tergiversado para protegerlo a él y a la policía (Enrique Jaramillo Levi, Luminoso tiempo gris, 2002, ficción).

Tampoco se le ve todavía el final al que está padeciendo, desde hace cinco, Cosme Delclaux; pero el margen de esperanza es, en este caso, mucho más amplio, ya que, en la siniestramente larga lista de los secuestros de ETA, se cuentan con los dedos de una mano los que no han terminado con la liberación de la víctima (El País, prensa, 21-5-1997, política y economía).

\subsection{Izquierdo}

Si repasamos los significados atribuidos al término por los diccionarios tan solo llama la atención por su carácter peyorativo el de 'torcido'. Ya en Autoridades 1734 encontramos esta definición: «Vale tambien lo mifmo que torcido, ó no recto, phyfica ò moralmente; aunque en lo morál fe dice mas cultamente Sinieftro». En el DRAE de 2001 se mantiene lo siguiente: «Torcido (que no es recto)».

Lo curioso es que nuestra exhaustiva búsqueda en el corpus no proporciona ejemplos que demuestren este empleo. Puede exponerse únicamente un pasaje en el siglo XVII que podría estar relacionado con este sentido. Pero ni siquiera puede asegurarse que ese sea su verdadero uso:

Dices muy ponderado, y con cara como si entendieras lo que culpas, que todos son sueños de hombres menesterosos o mal ocupados o no ocupados; sueños parecen por las señas de vuestra Señoría, de vuestra merced y de vuestra Excelencia, que este género de gente desvelada en remendar el mundo y enderezar las costumbres son el alborozo de los noveleros y el negocio de los vanos. Y por que vuestra merced conozca cuán izquierdo discurso tiene, quiero razonar algo, camino de la verdad (Francisco de Quevedo y Villegas, El chitón de las tarabillas, 1630, p. didáctica).

Observamos en la definición de Autoridades que los diccionarios informaban de que 'torcido' podía referirse tanto a lo físico como a lo psicológico, y es precisamente este último aspecto con el que lo podríamos relacionar aquí. De todas formas, tratándose de un significado que aparece aludido constantemente en los diccionarios a lo largo de la historia, 
deberíamos haber encontrado una gran cantidad de ejemplos de este tipo. Tengamos en cuenta que este sentido de 'torcido' aparece relacionado con la izquierda en la misma medida en que la derecha se identifica etimológicamente con el concepto de 'rectitud'.

\section{(Matrimonio) de la mano izquierda}

Encontramos recogida la expresión matrimonio de la mano izquierda en el DRAE2001 (s. v. matrimonio): «(Porque en la ceremonia nupcial el esposo daba a la esposa la mano izquierda). El contraído entre un príncipe y una mujer de linaje inferior, o viceversa, en el cual cada cónyuge conservaba su condición anterior». La primera edición académica que recogía esta expresión era la de 1869. Por otra parte, el $D E A$ recoge de la mano izquierda (s. v. mano): define su empleo como «raro» y la define como «bastardo o ilegítimo». Es, por tanto, bastante probable que exista una relación entre ambas expresiones.

Hemos hallado ejemplos de esta expresión en los siglos XIX y XX, pero en ninguno de ellos aparece el término matrimonio. Estos son los casos:

He sido hasta reina, reina de la mano izquierda, como dicen los franceses, pero tan dueña de la situación, que, a haber querido meterme en tales vulgaridades, hubiese cambiado ministerios y trastornado países (Vicente Blasco Ibáñez, Entre naranjos, 1900, literario).

Y estamos lo que se dice al día: que si los niños plus ultra, que si la maxifalda o la minifalda, que si los toros drogados o afeitados, o por barbar, o la ofrenda al apóstol, o la lista de hijos dilectos, predilectos y naturales, o sea, vamos, los de la mano $i z-$ quierda... ¡Pues anda, que no hay temas de charla ni nada que digamos! (Alonso Zamora Vicente, A traque barraque, 1972, literario).

\section{Echarlo todo a mano izquierda}

Esta expresión aparece en Autoridades 1734 (s. v. izquierda) con esta definición: «Phrafe que equivale à tener coftumbre de juzgar mal de las acciones de los otros, examinandolas menudamente para hallar en ellas alguna malicia». Sigue apareciendo en las ediciones académicas hasta 1791; sin embargo, no la he encontrado documentada en el CORDE.

\section{Entrarle a alguien una persona por el ojo izquierdo}

Esta locución aparece por primera vez en la edición del Diccionario Manual de 1984 bajo la forma entrar por el ojo derecho, o por el ojo izquierdo con el significado de «ser aceptada con simpatía o antipatía» $(s v$. ojo). En el DRAE-2001 ya aparece de forma diferenciada entrarle a alguien una persona por el ojo izquierdo: «ser vista con antipatía», empleo caracterizado como coloquial. A pesar de ser una expresión bastante conocida en nuestro idioma, no he encontrado ejemplos de ella en el corpus.

\section{Con el pie izquierdo}

Esta es otra expresión muy utilizada y compartida también por otras lenguas. La primera edición académica que la recoge es la del Diccionario manual de 1985 (s. v. pie): levantarse uno con el pie izquierdo, con el significado de «tener un día de mala fortuna».

También aparece recogida en los tres diccionarios actuales (s. v. pie). El DRAE-2001 la define como: «Con mal agüero, con mala fortuna». El $D E A$ introduce en la misma 
definición las cuatro locuciones análogas que encontramos en español: con buen (o mal) pie, o con el pie derecho (o izquierdo). La definición propuesta es: «Con buena (o mala) suerte, o con mucho (o poco) acierto». Añade además que aparece normalmente con los verbos levantarse, entrar o empezar. Por su parte, el DUE define con el pie izquierdo con la locución «con mal pie», que a su vez significa «con desgracia, mala suerte, o desacierto»; también explica que suele aparecer con empezar, entrar y verbos análogos.

Son abundantes los ejemplos antiguos en los que se alude a la superstición que relaciona el pie izquierdo con la mala suerte, aunque no es hasta el siglo XX donde la expresión con el pie izquierdo pierde constantemente su sentido literal:

Decididamente, hoy también se había levantado con el pie izquierdo (Juan Marsé, Últimas tardes con Teresa, 1966, literario).

Un caso del CREA:

El mundo y yo hoy no nos queremos

¿Se han levantado con el pie izquierdo? Si, imagino que sí.

Bueno hoy es uno de esos días. Quedarse unos "segundos" en la cama para averiguar que vas 30 minutos tarde al trabajo. No encontrar la media que hace falta, perder las llaves de la casa, quemar el pan del desayuno... son días fenomenales (04206009. Weblog 2004, efímero, 2004, miscelánea).

\section{Batear alguien por la izquierda}

Esta locución aparece únicamente en el DRAE-2001 (s. v. izquierdo $)^{6}$, que es la primera edición académica que la incluye y la define de esta manera: «Ser homosexual». Eso sí, el propio diccionario limita su empleo a México y al registro coloquial.

La incluimos aquí puesto que, a pesar de no contener un sentido peyorativo real, es probable que verdaderamente sí pueda utilizarse con ciertas connotaciones negativas, como las que a menudo rodean lo concerniente a la homosexualidad.

Hemos encontrado este pasaje en el CREA. Aunque se trata de un fragmento de Camilo José Cela, en él encontramos varios americanismos:

Los sábados conviene ir bien aseados, ponernos camisa limpia, tomar el ómnibus de Tucson a Nogales, ahora es de balde y además dan chocolate, bailar un corrido con Clarita Gavilán la del anuncio de La Voz de Nogales, el mestizo Diego Diego batea por la izquierda, ustedes ya entienden, y su esposa Clarita se tuvo que buscar su apaño para tranquilizarse, lleva ya mucho tiempo de cacuma de pobres pero aún le quedan ganas de jarana, Clarita Gavilán es muy alegre y no piensa ponerse las bragas para morirse, si Dios la quiere en el cielo no le va a andar revisando la ropa... (Camilo José Cela y Trulock, Cristo versus Arizona, 1988, ficción).

\section{Por izquierda}

Otra locución recogida también por el DRAE por primera vez en 2001 (s. v. izquier$d o)^{7}$ es por izquierda: «Ilegalmente, sin rectitud, con dobleces»; su empleo está restrin-

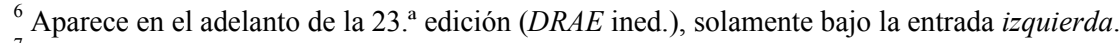

${ }^{7}$ Como en el caso anterior, esta expresión pasa a formar parte de la entrada izquierda en el adelanto de la nueva edición (DRAE ined.).
} 
gido al español de Argentina. Lo que más nos llama la atención es la primera parte de la definición, es decir, el matiz de 'ilegalmente'.

Encontramos en el CREA este ejemplo, perteneciente en efecto al español argentino, que nos ilustra perfectamente su significado:

Mayorga negó que en la ESMA se les hubieran cortado los dedos con una sierra a los detenidos para que no fueran identificables por las impresiones digitales. " $i M e n-$ tira! Lo único que teníamos en la ESMA era picana". También disintió con la conducción naval de la época. "Para mí habría que haber fusilado en River con CocaCola gratis y televisándolo. Yo no estaba de acuerdo con eso de trabajar por izquier$d a$ ". Trabajar por izquierda es el eufemismo argentino para describir procedimientos ilegales y clandestinos (Horacio Verbitsky, El vuelo, 1995, política y economía).

\section{Izquierdear}

Este verbo ya aparece en Autoridades 1734 como «baftardear ò torcerfe, phyfica ò moralmente». El $D R A E-2001$ lo define como: «Apartarse de lo que dictan la razón y el juicio». El $D U E$, como: «Obrar insensatamente» (lo incluye como un significado no usual). El $D E A$ no lo contempla.

Aparece reflejado en el CORDE ya en el siglo XV:

E si dios quisiera e esa hora nuestros fados lo consintieran e nuestro entendimiento non izquerdara el verdadero juizio, asaz bastava aquel sonar e señial bien pudieran dar lugar qu'el fierro demostrara los escondrijos (Enrique de Villena, Traducción y glosas de la Eneida. Libros I-III, 1427-1428, literario).

Curiosamente, en el único caso reflejado en el CREA con este verbo encontramos un significado especial, pues se mezcla su sentido con el valor que izquierda tiene en términos políticos; todo ello, en mi opinión, hace que se junte en el término una doble visión negativa:

Soy, como siempre, constitucional y liberal a derechas, que jamás ha izquierdeado (Pedro Ortiz-Armengol, Aviraneta o la intriga, 1994, ciencias sociales).

\subsection{Zurdo}

Si atendemos a lo que se dice del término en los distintos diccionarios a lo largo de la historia no encontramos casi nada resaltable por su visión negativa. Por lo que se refiere al empleo del término en la actualidad, el único significado negativo recogido por los diccionarios es el que define el $D E A$ como «torpe o desmañado»; el diccionario califica este empleo de «raro». En el CORDE aparece este empleo en bastantes pasajes de este tipo:

Es verdad que soy barbero,

y no me tengo por zurdo,

y espero de un día a otro

mi licencia; mas pregunto,

¿quién diablos me da dinero

para poner un tenducho?

(Manuel Bretón de los Herreros, Dios los cría y ellos se juntan, 1841, literario).

En cambio, analizando los casos que ofrece el CREA, no parece que en la actualidad los empleos de zurdo se alejen de su sentido más frecuente. 
Ahí la juega un zurdo

Desde Autoridades 1739 (s. v. zurdo) aparece recogida la expresión ahí la juega un zurdo, con el significado: «Phrafe ponderativa, con que fe pondera por lo regular ironicamente la habilidad, deftreza, è inteligencia de algun fugeto en el acierto de alguna accion, que ha executado». Encontramos esta expresión en muchas ediciones - aunque no en todas- del diccionario académico, pero ya no aparece desde 1992. Tampoco la recogen el $D E A$ ni el $D U E$.

El CORDE ofrece este fragmento con esta locución, aunque la encontramos con ligeras variaciones:

D. Chisme Agur,

y á madamas mis atentas expresiones.

Paje $10^{\circ}$ iAh! Cuidado

que nada de esto se sepa.

D. Chisme ¿Cómo es fácil? ¡Pues ahí es

algún zurdo quien lo juega!

(Ramón de la Cruz, El Caballero Don Chisme, 1766, literario).

En el $C R E A$ no aparecen casos.

A zurdas

Otra expresión es a zurdas, que encontramos también en 1739, en Autoridades (s. v. zurdo), definida como: «Modo adverbial, que vale con la mano zurda, ó al reves, ó al contrario de como fe debia hacer». Esta significado se divide con el paso del tiempo, en las ediciones académicas, en dos acepciones, de manera que en el DRAE-2001 ( $s$. v. zurdo) aparece, como segunda acepción de a zurdas: «Al contrario de como se debía hacer». Sin embargo, el adelanto de la 23. ${ }^{a}$ edición ya no recoge esta expresión.

Tampoco lo hace el $D E A$. En cambio, el $D U E$ (s. v. zurdo), de manera análoga al $D R A E$, separa dos acepciones para a zurdas, de las cuales la segunda es «de manera contraria a como se debe hacer»; de todas formas, califica su empleo de poco usual.

Encontramos empleos peyorativos con esta expresión en el CORDE en pasajes como:

Madres, las que tenéis hijas,

ansí Dios os dé ventura,

que no se las deis a calvos,

sino a gente de pelusa.

Escarmentad en mí todas;

que me casaron a zurdas

con un capón de cabeza,

desbarbado hasta la nuca.

(Francisco de Quevedo y Villegas, Poesías, 1597-1645, literario).

No aparece, sin embargo, ningún empleo de este tipo en el CREA.

No ser zurdo

También existe la expresión no ser zurdo, que recoge Autoridades en 1739 (s. v. zurdo) con esta definición: «Phrafe ponderativa, con que fe explica fer alguno mui ha- 
bil, y dieftro en la materia de que fe trata». El sentido esencial de esta definición permanece en prácticamente todos los diccionarios. Tanto en la edición de 2001 del $D R A E$ (s. v. zurdo) como en el adelanto de la $23^{\mathrm{a}}$ (DRAE ined.: s. v. zurdo) aparece como definición de esta expresión — con la aclaración de que se emplea más en América«no ser cojo ni manco», locución que a su vez se define (s. v. cojo) como «ser muy inteligente y experimentado en lo que le toca». El DUE (s. v. zurdo) define no ser zurdo como «ser listo o hábil», aunque califica también este empleo de no usual. El DEA no recoge la expresión.

Aparece en el CORDE este ejemplo:

Se trata, mi querido amigo, de un jueguito muy conocido en la cancha. Es una letanía muy vieja y muy sabida. Vaya aprendiendo, pues, a no ser zurdo y a no dejarse cazar como un pichón en trampas tan groseras (Eugenio Cambaceres, Música sentimental: silbidos de un vago, 1884, literario).

En el CREA no he encontrado casos.

\section{CONCLUSIONES}

Frente a todos estos términos y expresiones, solo encontramos un caso en el que la izquierda se relaciona con algo bueno: se trata de la expresión (tener) mano izquierda, que aparece en los diccionarios con el significado de 'ser hábil, astuto'. Sin embargo, parece que este sentido positivo nace precisamente de la torpeza que se le atribuye generalmente a nuestra mano zurda.

Por tanto, nos encontramos con una larga lista de casos que dan muestra de la fuerte interdicción que existe en nuestra lengua - como en la mayoría- sobre todo lo relacionado con la izquierda. He resaltado en este artículo solamente los casos más evidentes, pero hay otros que también podrían formar parte de los anteriores si se profundiza un poco en su origen. De todos ellos, uno que resulta especialmente interesante es el de los significados que adquieren derecha e izquierda en el terreno de la política. Partiendo del hecho de que ambos conceptos nacieron a partir de la situación de los partidarios de una y otra ideología en la asamblea francesa en el período de la Revolución, ¿acaso no puede pensarse que los representantes socialmente menos favorecidos fueran situados a la izquierda del presidente por ser el lado derecho el honorífico por excelencia? Este asunto resulta de especial relevancia debido al gran empleo de ambos términos con connotaciones políticas en la actualidad.

Una conclusión clara que se extrae de la información aquí aportada es que, en efecto, el término izquierdo ha cumplido buena parte de su función eufemística, ya que, a pesar de formar parte de bastantes expresiones con significado peyorativo, el término en sí mismo no presenta ningún significado claramente negativo, sobre todo si lo comparamos con los empleos actuales - y no tan actuales - de su antecesor siniestro.

Evidentemente, otra prueba que demuestra las repercusiones en la lengua de la simbología a la que estamos aludiendo es la existencia de todo tipo de significados contrarios, es decir, positivos, si nos fijamos en los términos y expresiones relacionadas con 
la derecha, entre los que resultan más comunes: a derechas, con el pie derecho, entrar por el ojo derecho, diestro, destreza, etc.

\section{REFERENCIAS BIBLIOGRÁFICAS}

COROMINAS, Joan y José Antonio PaScual (1980-1991): Diccionario crítico etimológico castellano e hispánico, Madrid, Gredos.

DEA: vid. Manuel SECo Olimpia ANDRÉS y Gabino RAMOS (1999).

DECH: vid. Joan COROMINAS y José Antonio PASCUAL (1980-1991).

DRAE-2001: vid. REAL ACADEMIA ESPAÑOLA (2001a).

DUE: vid. María MOLINER (2007).

ERNOUT, Alfred y Antoine MEILLET (1985[1932]): Dictionnaire étymologique de la langue latine. Histoire des mots, Paris, Klincksieck.

HERTZ, Robert (1990 [1909]): «La preeminencia de la mano derecha. Estudio sobre la polaridad religiosa», en La muerte y la mano derecha, Madrid, Alianza, pp. 103-134.

KOURILSKY, Raoul y Pierre GRAPIN, dirs. (1971): Mano derecha y mano izquierda. Norma y lateralidad, Buenos Aires, Proteo.

MEILLET, Antoine (1948 [1906]): «Quelques hypothèses sur des interdictions de vocabulaire dans les langues indo-européennes», en Linguistique historique et linguistique générale, Paris, Librairie Ancienne Honoré Champion, pp. 281-291.

MOLINER, María (2007 [1966-1967]): Diccionario de uso del español, Madrid, Gredos.

NeEDHAm, Rodney, ed. (1973): Right and left. Essays on Dual Symbolic Classification, Chicago-London, The University of Chicago Press.

NTLLE: vid. REAL ACADEMIA ESPAÑOLA (2001b).

Real Academia Española $\left(2001 \mathrm{a}^{22}\right)$ : Diccionario de la lengua española, [en línea], $<$ http://www.rae.es $>$.

(ined. ${ }^{23}$ ): Diccionario de la lengua española, [en línea], <http://www.rae.es>.

SeCo, Manuel, Olimpia ANDRÉS y Gabino RAMOS (1999): Diccionario del español

actual, Madrid, Aguilar.

TOVAR Llorente, Antonio (1959): El Euskera y sus parientes, Madrid, Minotauro.

URÍA VARELA, Javier (1997): Tabú y eufemismo en latín, Amsterdam, Hakkert.

CORPUS

CORDE: Real ACADEMia Española: Corpus diacrónico del español [en línea], $<$ http://www.rae.es> [Consulta: 1/9/2008-30/6/2010].

CREA: ReAl ACADEMia Española: Corpus de referencia del español actual [en línea], $<$ http://www.rae.es> [Consulta: 1/9/2008-30/6/2010]. 